\title{
Occurrence of Typhoidal and Non-Typhoidal Salmonellae among Poultry Workers in the Southern, Nigeria
}

\author{
Etanguno Effiong Owowo', Veronica J. Umoh'1, Iquo Effiong Okon ${ }^{2}$ \\ ${ }^{1}$ Department of Microbiology, Akwa Ibom State University (AKSU), Mkpat Enin, Nigeria \\ ${ }^{2}$ Health Initiative for Stability \& Safety in Africa (HIFASS), Uyo, Nigeria \\ Email: etangunoowowo@aksu.edu.ng, iquokon@gmail.com
}

How to cite this paper: Owowo, E.E., Umoh, V.J. and Okon, I.E. (2019) Occurrence of Typhoidal and Non-Typhoidal Salmonellae among Poultry Workers in the Southern, Nigeria. Open Journal of Medical Microbiology, 9, 201-214.

https://doi.org/10.4236/ojmm.2019.94019

Received: October 21, 2019

Accepted: December 6, 2019

Published: December 9, 2019

Copyright () 2019 by author(s) and Scientific Research Publishing Inc. This work is licensed under the Creative Commons Attribution International License (CC BY 4.0).

http://creativecommons.org/licenses/by/4.0/

\begin{abstract}
Typhoid fever and non-typhoidal salmonellosis remain endemic in most developing countries with large scale transmission through contaminated food and drinking water. Since the early 2000s, poultry has also been found to be a common food source for Salmonella enteritidis infections. A total of 500 blood, stool, cloaca swab and egg shell swab specimens were collected respectively from poultry, non-poultry workers and birds in Akwa Ibom State and screened for Salmonella species using standard cultural and serological techniques. The overall prevalence rate was 117 (23.4\%). Salmonella species were distributed in all the three senatorial districts of the State, percentage distribution of Salmonella isolates was 42 (25\%) for Uyo, 35 (20.8\%) for Eket and $40(23.8 \%)$ were isolated from Ikot Ekpene senatorial districts. Out of 372 human subjects screened 77 (20.7\%) were positive and 38 (20.4\%) were isolated from non-poultry workers while 39 (21.0\%) were isolated from poultry Staff in the three senatorial districts. Out of 128 samples of poultry products analysed $40(31.3 \%)$ were isolated. $23(18 \%)$ were isolated from cloaca swabs while $17(13.3 \%)$ were isolated from egg shell swabs. In this study, all the serological significant Typhoid fever cases were confirmed by blood culture. According to sero-grouping and source of sample collection $23.9 \%$ S. typhi was isolated from human followed by $S$. paratyphi A (20.5\%) while $S$. enteritidis and $S$. gallinarum (19.7\%). Among poultry products $S$. gallinarum, $S$. enteritidis, $S$, pullorum, $S$. paratyphi A, and $S$. typhimurium were isolated from bird Cloaca swab and Egg shell swab. Salmonella pullorum and $S$. typhi were not isolated from human and poultry respectively. High prevalence of Salmonella serovars such as $S$. gallinarium, $S$. typhi, S. Typhimurium and $S$. enteritidis with regular consumption of poultry and eggs without proper disinfection and appropriate boiling represent a serious public health risk in
\end{abstract}


Akwa Ibom State. Demographic data obtained in this study showed that majority of the poultry workers across the three senatorial districts were within the ages of 21 to 30 (34\%), 39\% were none graduate while $30.4 \%$ were secondary school leavers. Fever was recorded as the highest clinical signs and symptoms followed by headache, abdominal cramps, diarrhoea and vomiting. Generally, all the isolates identified as Salmonella were tested for their susceptibility to antimicrobial agents. The results showed that Amoxacillin-Clavulanic acid was $100 \%$ susceptible to $S$. gallinarum, $S$. paratyphi A, 93\% susceptible to $S$. typhi and $80 \%$ to $S$. typhimurium, $S$. enteritidis and $S$ pullorum. Salmonella gallinarum was $100 \%$ sensitive to Ciprofloxacin and $S$. pullorum, whereas all isolates were $100 \%$ resistant to Oxacillin and Tylosin antibacterial agents used. The emergence of multiple drugs resistant Salmonella from human and poultry shows that the continuous use of drugs in poultry as growth promoters should be re-examined. Other factors as sources of Salmonella contamination in farms can be minimized by good hygienic practices and biosecurity measures.

\section{Keywords}

Poultry, Salmonella, Poultry Workers, Antibiogram

\section{Introduction}

The genus Salmonella is a rod shaped, gram negative, flagellated, facultative anaerobe that belongs to the family Enterobacteriaceae [1]. It consists of two separate species; Salmonella bongori and Salmonella enterica and encompasses over 2500 known serotypes, all of which are considered potential human pathogen [2]. Salmonella causing human disease is divided into human restricted invasive typhoidal serotypes ( $S$. enterica var. Typhi and S. enterica var. Paratyphi $A$ ) and thousands of non-typhoidal Salmonella serotypes known as NTS serotypes [3].

Typhoid fever and non-typhoidal salmonellosis remain endemic in most developing countries with large scale transmission through contaminated food and drinking water. Typhoid fever results from Salmonella typhi. A person infected with the Salmonella bacterium usually has fever, abdominal cramps, and diarrhea beginning 12 to 72 hours after consuming contaminated food or beverage. The illness usually lasts 4 to 7 days, and most persons recover without antibiotic treatment. However, the diarrhea can be severe, and the person may be ill enough to require hospitalization [4]. Certain cases of salmonellosis are severe and often require antimicrobial therapy for treatment, thus resistance to antimicrobial drugs is a great concern [5].

Salmonella species are becoming increasingly resistant, making it more difficult to treat with severe infections [6].

The elderly, infants, and those with impaired immune systems may have a more severe illness. In these patients, the infection may spread from the intes- 
tines to the blood stream, and then to other body sites and can cause death unless the person is treated promptly with antibiotics. An estimated $95 \%$ of Salmonella infections are foodborne [7]. Salmonella enterica causes a number of significant poultry diseases and is also a major pathogen in humans. Most poultry infected by Salmonella become carriers; infection may also be fatal, depending on the particular serovar and the age of the bird at infection.

The Vi-antigen also occurs in Salmonella paratyphi $\mathrm{C}$ and $S$. dublin (a subtype of $S$. enteritidis). Specific antibodies are produced by the body: anti-O and anti-H (also called TO and TH). The humoral antibodies result in little protection. Protection is based on cellular immunity. The $\mathrm{O}$ - and $\mathrm{H}$-antigens are used in serological tests (Widal) [named after the French physician Ferdinand Widal, 1862-1929]. Since all Salmonella (not only Salmonella typhi) and all bacteria related to Salmonella possess similar antigens, there are many cross reactions (the test is non-specific). The test also has quite low sensitivity. This means that the contribution of serology is limited in many clinical situations. In animal populations, Salmonella was most frequently detected in poultry flocks. Egg and bakery products were the most common sources of Salmonella outbreaks, whereas broiler meat was an important source for both Salmonella and Campylobacter outbreaks [8].

Poultry is an essential component of the Nigerian economy, providing income for small scale farmers and a good source of high quality protein for the ever-growing population of Nigeria. In livestock production, poultry occupies a prominent position in the provision of animal protein and this account for about $25 \%$ of local meat production in Nigeria [9]. With the great expansion of poultry rearing and farming, Salmonellosis has become an important public health problem in Nigeria and other parts of the world, causing heavy economic loses through substantial morbidity and mortality in humans and animals [10]. Horizontal and vertical transmissions are important in the epidemiology of Salmonellosis worldwide, especially fowl typhoid and pullorum disease [11] [12]. Anyone can get a Salmonella infection, but the elderly, infants, and persons with impaired immune systems are at increased risk for serious illness. In these persons, a relatively small number of Salmonella bacteria can cause severe illness. In outbreaks, most of the deaths caused by Salmonella enteritidis have occurred among persons in poultry farms, nursing homes and hospitals. Egg-containing dishes prepared for any of these high-risk persons, whether in hospitals, nursing homes, restaurants, or at home, should use pasteurized eggs [13]. Furthermore, multiple antibiotic resistance has been reported to be common among Salmonella species, particularly in the developing countries [14] [15]. In Lagos, Nigeria, out of 85,189 confirmed cases of Salmonella associated diseases, 880 deaths were recorded between 1999 and 2008, giving a case-fatality rate of $1.03 \%$ [16]. In view of this, effective prevention and control of Salmonella infection are important for the profitable expansion of poultry industry in Nigeria. These measures cannot be undertaken unless the status of the disease is elucidated. Since infection by Salmonella is reported to be endemic in Nigeria [17], analysis of 
Salmonella strains and genetic diversity is important for epidemiology of the infection.

\section{Aims of the study}

1) The general aim of this study is to determine the Salmonella carrier status of poultry workers in Akwa Ibom State and to investigate their possible roles as reservoirs of Salmonella infections.

2) To determine the Salmonella types circulating in the study population using phenotypic and serologic methods.

3) To establish the relatedness using genetic diversity among the Salmonella strains isolated.

4) To investigate the antibiogram of Salmonella isolates from poultry, poultry workers and general population (control group).

\section{Materials and Methods}

The study design: The study is a cross-sectional study.

\section{Study area and population}

The study was conducted in the three senatorial zones, Ikot Ekpene (IK), Eket (EK) and Uyo (UY) Akwa Ibom State. Akwa Ibom State is located on longitude $8^{\circ} 30^{\prime}$ and latitude $5^{\circ} 30^{\prime}$ in the Southern region of Nigeria; it covers an area of $455 \mathrm{~km}^{2}$. The major occupation of the people living in Akwa Ibom is civil and farming. Blood and stool samples were collected from poultry workers in each senatorial zone. A total of 372 blood and stool samples were collected from the three zones, one hundred and eighty-six (186) samples of blood and stool were from human subjects and one hundred and twenty-eight (128) samples from poultry, giving a total of 500 samples from the three zones.

\section{Preliminary investigation}

The chosen hospitals and poultry farms were visited to obtain official permission to conduct the study and to discuss the feasibility of the study and to seek the cooperation of the Clinicians, Medical Laboratory Scientists and poultry managers or owners.

\section{Ethical approval}

Ethical clearance and approval were obtained from the department of Research and Education Ethical Committee of the State Ministry of Health, to collect specimens from both Government and Private owned poultry facilities and health facilities within the study area.

\section{Inclusion criteria}

Subjects that included in the study were between 14 years to 65 years old and above, working as poultry staff or owners and non-poultry workers in the study area. For the purpose of analysis, subjects were divided into two groups: Group 1: were subjects with or without symptoms of typhoid fever working in poultry farms in the study area.

Group 2: were Subjects with or without clinical typhoid fever but non poultry workers. They served as control. 


\section{Exclusion criteria}

Market handlers of poultry products were not included in the study due to possible cross contamination of the product. The study was conducted between January 2015 and December 2016 (12 months period).

\section{Sampling methods}

A total of 372 blood and stool samples were collected from patients in the three zones who presented with or without clinical symptoms of enteric fever. In humans, $5 \mathrm{mls}$ of venous blood were taken aseptically with sterile vacutainer for serological analysis. Stool samples were also collected using wide mouth sterile universal containers from humans for culture. Poultry cloaca swabs and egg swabs were collected using sterile swab stick, the nature of sample, date and time of collections boldly written. The samples were transported to the laboratory with minimum delay to avoid death of enteric pathogens [18] [19]. Blood was inoculated into Thioglycollate broth while stool, egg and cloaca swabs were inoculated into selenite-F broth for $24 \mathrm{hrs}$ and sub-cultured onto Deoxycholate Citrate Agar (DCA) and Salmonella-Shigella Agar (SSA).

\section{Isolation of Salmonella from egg and cloaca swabs.}

Egg swabs and cloaca swabs were inoculated into selenite-F broth for $6 \mathrm{hrs}$ enrichment and sub-cultured onto Deoxycholate Citrate Agar (DCA) and Salmonella-Shigella Agar (SSA) and then incubated at $37^{\circ} \mathrm{C}$ for 18 to $24 \mathrm{hr}$ for growth [20].

\section{Preparation of pure and stock cultures}

Plates were examined after overnight incubation. Non-Lactose-fermenting colonies picked from Salmonella-Shigella Agar and Deoxycholate Citrate Agar, characteristic of Salmonella were sub-cultured on nutrient agar to obtain pure isolates. The pure isolates were stored on nutrient agar slants and preserved in refrigerator at about $4^{\circ} \mathrm{C}$ to $8^{\circ} \mathrm{C}$. Transfer onto fresh agar slopes was made at regular interval of one week [21]. Plates showing no growth or growth of lactose fermenters were re-incubated for 24 hours before discarding as being negative for Salmonella organisms.

\section{Biochemical characterization of the bacterial isolates}

Isolates were identified using biochemical tests and API $20 \mathrm{E}$ for confirmation; API 20E is a standardized identification system for Enterobacteriaceae and other non-fastidious Gram negative rods which use 20 miniaturized biochemical tests and a database. Organism identification is based on $\mathrm{pH}$ change and substrate utilization. An overnight culture of presumptive Salmonella colonies on selective media was obtained and the test was carried out and interpreted as recommended by the manufacturer.

\section{Serological identification of Salmonella}

Serotyping of the salmonella isolates was done according to Kauffman-White Scheme [22] involving the use of Salmonella antisera. Polyvalent Salmonella antisera A-G, A-S, surface antigen, phase 1 and phase 2 flagellar $\mathrm{H}$ antigens (Denka Seiken, Japan) were used for the serological identification of Salmonella. Antigenic suspension of each Salmonella isolate was made by suspending about 3 - 5 
colonies of pure culture of isolate in $0.5 \mathrm{ml}$ physiological saline. A drop of each polyvalent antiserum and $30 \mu \mathrm{l}$ of physiological saline was placed on a clean glass slide and used as control. About $10 \mu \mathrm{l}$ of antigenic suspension was placed on a clean glass slide, serum and physiological saline were on the other end of the glass slide. The reagents were mixed by tilting the glass slide back and forth for two minutes and the agglutination pattern was observed. Agglutination was observed with light through the slide. Strong agglutination observed within one minute was recorded as positive while delayed or weak agglutination was considered negative. About $0.2 \mathrm{ml}$ antigenic suspension was dispensed in $2 \mathrm{ml}$ physiological saline and heated to about $121^{\circ} \mathrm{C}$ for $15 \mathrm{~min}$. the heated solution was centrifuged at $900 \times \mathrm{g}$ for $20 \mathrm{~min}$. the supernatant was discarded. The precipitate was suspended with $0.2 \mathrm{ml}$ physiological saline and was used as heated cell suspension. A drop of the polyvalent antiserum and $30 \mu \mathrm{l}$ physiological saline was placed on a cleaned glass slide and serve as control. On another glass slide $10 \mu \mathrm{l}$ of antigenic suspension was mixed with serum and physiological saline by tilting the glass slide back and forth for one minute and agglutination pattern was observed and results recorded appropriately.

\section{Antimicrobial sensitivity test}

Antibacterial Sensitivity testing was performed according to Kirby-Bauer disk diffusion method recommended by the NCCLS [23] and CLSI [24]. The antimicrobial assay was carried out using Mueller Hinton agar and was tested in vitro for susceptibility to nine different antibiotics.

\section{Results}

See the tables and Figure.

\section{Discussion}

Typhoidal and non-typhoidal Salmonella species infection has emerged an important public health risk in Nigeria. They cause infection in both human and poultry and several studies have documented that poultry animals are the main carrier of non-typhoidal salomonellosis in developed and developing countries (22). Investigation of outbreaks and sporadic cases of salmonellosis have indicated repeatedly that the most common sources of non-typoidal infections in developing countries are undercooked or raw eggs, and contaminated poultry products.

This research has revealed the presence of Typhoidal and non-typhoidal Salmonella species in poultry products, (egg shells and cloaca) and among the workers with overall isolation rate of 117 (23.4\%) (Table 1). This finding in itself is not surprising since Salmonella is reported to be poultry persistent pathogens capable of surviving and proliferating in diverse environments including eggs, eggs shells and gastrointestinal tract of poultry [25]. Their prevalence is higher than $10.9 \%$ reported by Muhammed et al., [10] in Jos, plateau. Salmonella isolates were found in all the sample sources used in this study; including poultry workers, poultry products and also in the control subjects. This is attributed to 
poor hygienic practices by this class of subjects (Table $2 \&$ Table 3 ). This is in support of the report of Ibrahim et al., [8] that Salmonella species were isolated from farmers, egg swab and birds cloaca in Egypt. However, the study showed no significant difference at $(\mathrm{p}<0.05)$ in the rate of infection between the poultry workers and non-poultry subjects, but showed significant level between the isolates from poultry products and poultry workers (human) in all the senatorial districts studied. This is in support of the recent report that the prevalence of Salmonella species in poultry products and farmers are up to $2.2 \%$ higher in

Table 1. Prevalence rate of Salmonella isolates among the senatorial districts.

\begin{tabular}{ccccccc}
\hline \multicolumn{7}{c}{ Source Samp. no Senatorial districts } \\
& \multicolumn{7}{c}{ Uyo } & Eket & IK & Total & Pos (\%) \\
\hline Non-poultr & 186 & 14 & 11 & 13 & 38 & 20.4 \\
Poultry & 186 & 15 & 12 & 12 & 39 & 21.3 \\
Products & 128 & 13 & 12 & 15 & 40 & 31.3 \\
Total & 500 & 42 & 35 & 40 & 117 & 23.4 \\
\hline
\end{tabular}

IK: Ikot Ekpene, EK: Eket, Poultr: Poultry.

Table 2. Socio-demographic characteristics of poultry workers in Akwa Ibom State.

\begin{tabular}{|c|c|c|c|c|}
\hline Age Group (yrs) & Uyo & Eket & Ik Total (\%) & $\mathrm{P}$-value \\
\hline $15-20$ & 21 & 18 & $2261(13.7)$ & \\
\hline $21-30$ & 40 & 43 & $46129(33.9)$ & \\
\hline $31-45$ & 32 & 30 & $3193(25.0)$ & \\
\hline $46>50$ & 31 & 33 & 2589 (23.9) & \\
\hline Mean \pm SD & $31 \pm 7.79$ & $31 \pm 10.30$ & $31 \pm 10.68$ & 1.000 \\
\hline \multicolumn{5}{|c|}{ Gender } \\
\hline Male & 72 & 69 & $63204(54.8)$ & \\
\hline Female & 52 & 55 & $61168(45.2)$ & \\
\hline Mean \pm SD & $62 \pm 14.14$ & $62 \pm 9.90$ & $62.00 \pm 1.41$ & 1.000 \\
\hline \multicolumn{5}{|c|}{ Marital Status } \\
\hline Single & 32 & 39 & $33104(28.0)$ & \\
\hline Md/Co-habit & 79 & 70 & $75224(60.2)$ & \\
\hline Septed/dived & 13 & 15 & $1644(11.8)$ & \\
\hline Mean $\pm S D$ & $41.33 \pm 33.98$ & $41.33 \pm 27.57$ & $41.33 \pm 30.37$ & 1.000 \\
\hline \multicolumn{5}{|c|}{ Educational Status } \\
\hline Primary & 2 & 5 & $815(4.0)$ & \\
\hline Secondary & 33 & 38 & $42113(30.0)$ & \\
\hline Tertiary & 28 & 31 & $3998(26.3)$ & \\
\hline None & 61 & 50 & $35146(39.3)$ & \\
\hline Mean \pm SD & $31 \pm 24.18$ & $31 \pm 19.03$ & $31 \pm 15.60$ & 1.000 \\
\hline
\end{tabular}


Table 3. Socio-demographic characteristics of poultry workers in Akwa Ibom State.

\begin{tabular}{ccccc}
\hline Ressidence & Uyo & Eket & Ik Total (\%) & P-value \\
\hline Rural & 36 & 41 & $48125(33.6)$ & \\
Urban & 47 & 48 & $40135(36.3)$ & \\
Semi-urban & 41 & 35 & $36112(30.1)$ & \\
Mean \pm SD & $41.33 \pm 5.51$ & $41.33 \pm 6.51$ & $41.33 \pm 6.11$ & 1.000 \\
& \multicolumn{1}{c}{ Duration of work in poultry farm (yrs) } & \\
4 & 56 & 71 & $69196(52.7)$ & \\
$1-5$ & 58 & 45 & $48151(40.6)$ & \\
$6-10$ & 10 & 6 & $723(6.2)$ & \\
$11-15$ & 0 & 2 & $02(0.5)$ & \\
$16-20$ & 0 & 0 & $00(0.0)$ & 1.000 \\
$>20$ & 0 & 0 & $00(0.0)$ & \\
Mean \pm SD & $\mathbf{2 0 . 6 7 \pm 2 8 . 4 3}$ & $\mathbf{2 0 . 6 7 \pm 3 0 . 1 4}$ & $\mathbf{2 0 . 6 7 \pm 3 0 . 1 7}$ & \\
\hline
\end{tabular}

Korea. That Salmonella typhimurium (10.3\%), (19.7\%) Salmonella enteritidis and Salmonella gallinarum samples were isolated from human and poultry products could be attributed to close contact between the farm workers, poultry and other animals raised in the farms, as the organisms also have a broad host range and the ability to adapt to condition in different animal and environment (Table 5). This is in agreement with Fasure et al., [25] who reported that Salmonella typhimurium and Salmonella enteritidis were isolated from poultry and asymptomatic poultry workers in Ogun State. Investigations have also shown that the prevalence of Salmonella enteritidis, in infected chickens and eggs in poultry farms of $18.5 \%$ is an earlier finding that infected raw egg shells or chickens were the major sources of salmonellosis to poultry farmers in Korea.

However, the isolation of $S$. typhimurium in cloaca swab (12.5\%) was less than $22.2 \%$ reported by Okonkwo et al., [26]. It supported the report by Baker et al., [22] that domestic animals are the major reservoir and foods of animal origin are the major vehicles of non-typhoidal infection in human such as Salmonella typhimurium. This agreed with the finding by House et al., [27] that the distribution of non-typhoidal Salmonella serovars among livestock from slaughterhouses were similar to those in human, which infected broiler-chicken is the major infection source of human salmonellosis. The isolation of this organism from bird's cloaca may be due to the presence of rodents and other insects, among whom have been reported to aid the distribution of Salmonella in poultry farms. Salmonella enteritidis was isolated from egg shell swabs (19.7\%).

The isolation rates of $S$. gallinarum and S.paratyphi $A$ were 19.7\% and 20.5\% respectively from birds (Table 4). Poultry birds can easily be infected by these organisms through contaminated water source and vertical transmission by infected breeder flocks. This report is higher than $18.4 \%$ reported by Adley, et al., 
Table 4. Detection of Salmonella among poultry products in Akwa Ibom State. No tested $(\mathrm{N}=128)$.

\begin{tabular}{ccccc}
\hline \multicolumn{2}{c}{ Senatorial Districts } & \multicolumn{2}{c}{ Pos (\%) } \\
\hline Products & Uyo & Eket & IK & \\
\hline Cloacal swab & 08 & 06 & 09 & $23(18.0)$ \\
Egg swabs & 05 & 06 & 06 & $17(13.3)$ \\
Total & 13 & 12 & 15 & $40(31.3)$ \\
\hline
\end{tabular}

[28] and 1.3\% from droppings used for manure by Okwori et al., [14]. Mai et al., [29] also reported lower rate $8.9 \% S$. paratyphi $A$. These isolates are adapted to avian hosts, causing fowl typhoid and paratyphoid diseases in birds respectively. Their isolation poses a serious concern for commercial poultry workers. These diseases have the potential for horizontal and vertical transmission, also reported by Berchieri et al., [30]. Salmonella pullorum was isolated from poultry and egg shell at a prevalence of $6 \%$. Isolation of this organism from poultry may be due to the presence of rodents and other animals, which have been reported to aid the distribution of salmonellosis in poultry farms. Its occurrence is lower than $6.24 \%$ as reported by Ndiaye et al., [31]. The findings also agreed with Bagudo et al., [32] who reported $12.5 \%$ of Salmonella pullorum from droppings in Sokoto State, Nigeria.

Only 23.9\% occurrence of Salmonella typhi was obtained from humans. Salmonella typhi isolation may be due to poor sanitary conditions and unhygienic practices. Human can also serve as asymptomatic carriers for typhoidal infections (Table 5).

Isolation of the causative agent of typhoid by cultural technique has remained the gold standard for diagnosis of enteric fever. The definitive diagnosis of typhoid fever depends on the isolation of salmonella typhi from blood, stool, urine and other body fluids. Blood culture has remained the gold standard for diagnosis of typhoid fever. Although culture is associated with a lag period of at least $48 \mathrm{hr}$. for preliminary confirmation of infection, they remain an essential investigation considering the recent emergence of drug resistance among $S$. typhi.

The results of antibiogram revealed multidrug resistant in Salmonella serovars incriminated in both human and animal salmonellosis. Overall results showed that all serovars were $100 \%$ resistant to Tylosin and Oxacillin, $87.2 \%$ to Ampicillin, $71.8 \%$ to Ceftazidine, $66.7 \%$ to oxytetracycline and $60 \%$ to Ceftriaxone. In addition, five serovars were $100 \%$ resistant to over six different antibiotics. This could be attributed to misuse of drugs in both human and veterinary medicine, most especially for prophylaxis and as a growth promoter in poultry feeds. However, the antibacterial susceptibility test revealed $98 \%$ of the isolates were susceptible to Ciprofloxacin, $99.2 \%$ to Amoxacillin-clavulanic acid and $99.9 \%$ to Chloramphenicol. This shows that some fluoroquinolones and aminoglycosides still remain drug of choice for treatment of salmonellosis (Table 6). 
Table 5. Distribution of Salmonella isolates across the studied senatorial districts.

\begin{tabular}{ccccccccc}
\hline \multicolumn{7}{c}{ Salmonella species $(\mathrm{n}=117)$} \\
\hline Sen. S. gall S. typhim S. typhi S. ent. S. pull S. parat Total (\%) \\
\hline Uyo & 09 & 05 & 10 & 08 & 03 & 07 & 42 & 25.0 \\
Eket & 06 & 03 & 09 & 07 & 02 & 08 & 35 & 20.8 \\
IK & 08 & 04 & 09 & 08 & 02 & 09 & 40 & 23.8 \\
\hline
\end{tabular}

IK: Ikot Ekpene. S. gallinarum S. typhimurium S. typhi S. enteritidis S. pullorum S. paratyhi A.

Table 6. Distribution and phenotypic of multiple-drug resistance of Salmonella isolates.

\begin{tabular}{|c|c|c|c|c|c|c|c|c|c|}
\hline \multirow{2}{*}{ Salmonella } & \multicolumn{9}{|c|}{ Multi-drugs Susceptibility and Resistance pattern } \\
\hline & AMC & CIP & $\mathrm{C}$ & CAZ & OTC & AMP & OX & $\mathrm{CX}$ & $\mathrm{TN}$ \\
\hline S. galli & $S$ & $S$ & S & S & $\mathrm{R}$ & S & $\mathrm{R}$ & $S$ & $\mathrm{R}$ \\
\hline S. typ & $S$ & $S$ & S & S & S & $\mathrm{R}$ & $\mathrm{R}$ & $S$ & $\mathrm{R}$ \\
\hline S. typh & S & S & S & S & $\mathrm{R}$ & S & $\mathrm{R}$ & S & $\mathrm{R}$ \\
\hline S. parA & $S$ & $S$ & $S$ & $\mathrm{R}$ & $S$ & $S$ & $\mathrm{R}$ & $\mathrm{R}$ & $\mathrm{R}$ \\
\hline S. pull & S & $S$ & S & $S$ & $\mathrm{R}$ & $S$ & $\mathrm{R}$ & $\mathrm{R}$ & $\mathrm{R}$ \\
\hline S. enter & $S$ & $S$ & $S$ & $S$ & S & $\mathrm{R}$ & $\mathrm{R}$ & S & $\mathrm{R}$ \\
\hline
\end{tabular}

R: resistant, S: susceptibility. Amoxicillin-clavulanic acid (AMC), Ciprofloxacin (CIP), Chloramphenicol (C), Ceftazidime (CAZ), Ceftriaxone (CX), Oxytetracycline (OTC), Ampicillin (AMP), Oxacillin (OX), Ty$\operatorname{losin}(\mathrm{TN})$

\section{Conclusion}

It is important to remember that antimicrobial susceptibility testing and molecular epidemiological linkage cannot be elicited on serological diagnosis. Stool and blood culture before initiating antimicrobial therapy remain the diagnostic method of choice. In this study, I have ascertained the presence of Salmonella serovars in poultry farms, poultry and the non-poultry workers (control group) in Akwa Ibom State, Nigeria, where poultry birds and their product are major sources of food, while also untreated bird droppings are used for manure on vegetables commonly eaten raw by the public. High prevalence of Salmonella serovars such as $S$. gallinarum, $S$. typhi, S. typhimurium and $S$. enteritidis with regular consumption of poultry and eggs without proper disinfection and appropriate boiling represents a serious public health risk and the evidence for the initiation of Public Biosecurity Legislation (PBL) in order to prevent the increase rates of zoonotic Salmonella (Figure 1). The study also revealed emergence of multiple drugs resistant Salmonella from humans and poultry. This shows that the continuous use of drugs in poultry and its usage as a growth promoter in poultry feeds should be re-examined to reduce the wide spread and circulation of the resistant strains of Salmonella. Other factors identified as sources of Salmonella contamination in poultry farms can be minimized by good hygienic practices and bio-security measures. 


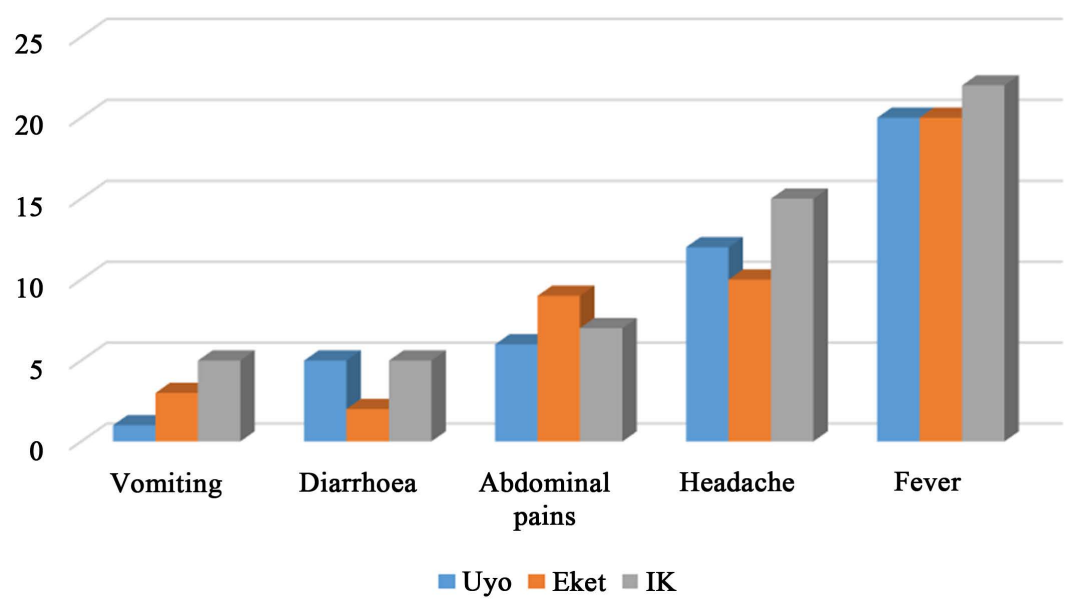

Figure 1. Distribution of clinical signs and symptoms of poultry and non-poultry workers in the three senatorial districts.

\section{Contribution to Knowledge}

1) Prevalence of harmful Salmonella serotypes was isolated among poultry workers in Akwa Ibom State.

2) Establishment of multiple drug resistance Salmonella was isolated among poultry farmers and poultry products in Akwa Ibom State.

3) Antibiotics such as ciprofloxacin, chloramphenicol and augmentin are recommended for the treatment of birds.

4) Establishment of genetic relatedness of Salmonella serotypes commonly distributed among poultry products and human.

\section{Recommendations}

Although most commercial poultry farmers claim to observe good standard management practices, the isolation of various Salmonella and subsequent antimicrobial resistance Salmonella serovars from poultry and humans in this study poses a great threat to disease management and for all stakeholders in the poultry industry in Nigeria. In view of this, suitable policies should be made to ensure strict compliance and regulation in poultry industry. The following recommendations should prove useful to ensure proper management and control of Salmonellosis.

1) Public awareness on health benefits on the consumption of contaminated poultry and poultry product contaminated by Salmonellae.

2) Strict compliance on good personal hygiene should be encouraged among poultry farms workers.

3) Biosecurity practices should be maintained in all poultry farms.

4) Partnership between professionals, government and stake holders in the poultry sector should be encouraged.

5) Continued surveillance by the researchers to determine regular antimicrobial susceptibility pattern in order to identify changes in resistance should be encouraged. 


\section{Conflicts of Interest}

The authors declare no conflicts of interest regarding the publication of this paper.

\section{References}

[1] Shivaprasad, H.L. (2000) Fowl Typhoid and Pullorum Disease. Revised Science Technology, 19, 405-424. https://doi.org/10.20506/rst.19.2.1222

[2] Baggesen, D.L., Sandvang, D. and Aarestrup, F.M. (2000) Characterisation of Salmonella Entericaserovar Typhimurium DT104 Isolated from Denmark and Comparison with Isolates from Europes and the United States. Journal Clinical Microbiology, 38, 1581-1586.

[3] Gordon, M.A., Feasey, N.A., Gordon, D., Robert, K.A. and Heyderman, R.S. (2012) Invasive Non-Typhoidal Salmonella Disease: An Emerging and Neglected Tropical Disease in Africa. The Lancet, 379, 2489-2499. https://doi.org/10.1016/S0140-6736(11)61752-2

[4] Ellaine, S., Robert, M.H., Frederick, J.A., Robert, V.T., Marc-Alain, W. and Sharon, L.R. (2011) Foodborne Illness Acquired in the United States. Emerging Infectious Disease, 17, 1338.

[5] Marrero-ortiz, R., Han, J., Lynne, A.M., David, D.E., Stemper, M.E., Farmer, D., Bukhardt, W., Nayak, R. and Forey, S.L. (2012) Genetic Characterization of Antimicrobial Resistance in Salmonella enterica Serovars Isolated from Dairy Cattle in Wisconsin. Food Research Internal, 45, 962-967. https://doi.org/10.1016/j.foodres.2011.04.013

[6] Rusul, G., Adzitey, F. and Huda, N. (2012) Prevalence and Antibiotics Resistance of Salmonella Serovars in Ducks, Duck Rearing and Processing Environments in Penang, Malaysia. Food Research International, 45, 947-952. https://doi.org/10.1016/j.foodres.2011.02.051

[7] Scallan, E., Hoekstra, R.M., Angulo, F.J., Tauxe, R.V., Widdowson, M.A., Roy, S.L., Jones, J.L. and Griffin, P.M. (2011) Foodborne Illness Acquired in the United States Major Pathogens. Emerging Infectious Disease, 17, 7-15.

https://doi.org/10.3201/eid1701.P11101

[8] Ibrahim, M.A., Emeash, H.H., Nahed, H.G. and Abdel-Halim, M.A. (2013) Seroepidemiological Studies on Poultry Salmonellosis and Its Public Health Importance. Journal of World's Poultry Research, 3, 18-21.

[9] Agbaje, M., Davies, S., Oyekunle, M.A., Ojo, O.E., Fasina, F.O. and Akinduti, P.A. (2010) Observation on the Occurrence and Transmission Pattern of Salmonella Gallinarum in Commercial Poultry in Ogun State, South Western Nigeria. African Journal of Microbiology Research, 4, 796-800.

[10] Muhammed, M., Muhammed, L.U., Ambali, A.G., Azard, S. and Barco, L. (2010) Prevalence of Salmonella Associated with Chick Mortality and Hatching and Their Susceptibility to Antimicrobial Agents. Veterinary Microbiology, 140, 131-135. https://doi.org/10.1016/j.vetmic.2009.07.009

[11] Zancan, F.T., Berchieri, J.A., Fernanders, A.S. and Gama, N.M.S.Q. (2000) Salmonella spp Investigation in Transport Boxes of Day-Old Birds. Brazillian Journal of Microbiology, 31, 230-232. https://doi.org/10.1590/S1517-83822000000300016

[12] Okwori, A.E.J., Ogbe, R.J., Chollom, S.C., Agada, G.O.A., Ujah, A., Okwori, E., Adeyanju, O.N. and Echeonwu, G.O.N. (2013) Isolation of Salmonella gallinarum from Poultry Droppings in Jos Metropolis, Plateau State, Nigeria. IOSR Journal of Agri- 
culture and Vertinary Science, 5, 41-44. http://www.iosrjournals.org https://doi.org/10.9790/2380-0524144

[13] CDC (Centers for Disease Control and Prevention) (2010) Multistate Outbreaks of Salmonella Infections Associated with Live Poultry, United States, 2007. MMWR Morbidity Mortality Weekly Report, 58, 25-29.

[14] Akinyemi, K.O., Basmiro, B.S. and Coker, A.O. (2007) Salmonellosis in Lagos, Nigeria: Incidence of Plasmodium falciparum-Associated Co-Infection, Patterns of Antimicrobial Resistance, and Emergence of Reduced Susceptibility to Fluoroquinolones. Journal of Health Population and Nutrition, 25, 351-358.

[15] Ibekwe, A.C., Okonkwo, I.O., Onunkwo, A.U., Donbraye, E., Babalola, E.T. and Onoja, B.A. (2008) Baseline Salmonella Agglutinin Titres in Apparently Healthy Freshmen in Awka South Eastern, Nigeria. Scientific Research and Essays, 3, 225-230.

[16] Akinyemi, K.O., Oshundare, Y.O., Oyeyinka, O.G. and Coker, A.O. (2012) A Retrospective Study of Community-Acquired Salmonella Infections in Patients Attending Public Hospistals in Lagos, Nigeria. Journal Infection Developing Countries, 5, 387-395. https://doi.org/10.3855/jidc.2120

[17] Adabara, N.U., Ezugwu, B.U., Momojimoh, A., Hashimu, Z. and Damisa, D. (2012) The Prevalence and Antibiotic Susceptibility Pattern of Salmonella typhi Patients Attending a Military Hospital in Minna Nigeria. Advance Preventive Medical, 2012, Article ID: 875419. https://doi.org/10.1155/2012/875419

[18] Cheesbrough, M. (2002) District Laboratory Practice in Tropical Countries. ECBS Edition, Cambridge University Press, Cambridge, Vol. 2, 182-187.

[19] Tam, F.C., Wang, M. and Dong, B. (2008) New Rapid Test for Paratyphoid a Fever: Usefulness, Cross-Detection, and Solution. Diagnostics Microbiology of Infectious Diseases, 62, 142-150. https://doi.org/10.1016/j.diagmicrobio.2008.07.002

[20] Grimont, P.A.D. and Weil, F. (2007) Antigenic Formulae of the Salmonella Sarovars. 9th Edition, WHO Collaborating Center for Reference and Research on Salmonella, Institute Pastuer, Paris.

[21] National Committee for Clinical Laboratory Standards (2004) Diagnostics and Treatment of Serious Antimicrobial Resistance of Salmonella Species. Journal of Infectious Diseases, 5, 188-203.

[22] Clinical and Laboratory Standard Institutes (CLSI) (2012) Performance Standards for Antimicrobial Susceptibility Testing; Twenty Second Informational Supplement. CLSI Document M100-S22. Clinical and Laboratory Standards Institute, Wayne.

[23] Baker, S., Favorov, M.O. and Dougan, G. (2010) Searching for the Elusive Typhoid Diagnostic. BMC Infectious Disease, 10, 45. https://doi.org/10.1186/1471-2334-10-45

[24] Wain, J. and Hosoglu, S. (2008) The Laboratory Diagnosis of Enteric Fever. Journal Infectious Developing Countries, 2, 421-425. https://doi.org/10.3855/jidc.155

[25] Fasure, A.K., Deji-Agboola, A.M. and Akinyemi, K.O. (2012) Antimicrobial Resistance Patterns and Emerging Fluoroquinolone Resistant Salmonella Isolates from Poultry and Asymptomatic Poultry Workers. African Journal of Microbiology Research, 6, 2610-2615. https://doi.org/10.5897/AJMR11.950

[26] Okonkwo, I.O., Nkang, A.O., Eyerefe, O.D., Abubakar, M.J., Ojezele, M.O. and Amusan, T.A. (2010) Incidence of Multi-Drug Resistant (MDR) Organisms in Some Poultry Feeds Sold in Calabar Metropolis, Nigeria. British Journal of Pharmacology and Toxicology, 1, 15-28.

[27] House, D., Ho, V.A., Diep, T.S., Chinh, N.T., Bay, P.V. and Vinh, H. (2008) Anti- 
bodies to the Vi Capsule of Salmonella typhi in the Serum of Typhoid Patients and Healthy Control Subjects from a Typhoid Endemic Region. Journal Infectious Development Countries, 2, 308-312. https://doi.org/10.3855/jidc. 227

[28] Adley, C., Dillion, C., Morris, C.P., Delappe, N. and Cormican, M. (2011) Prevalence of Salmonella in Pig Ear Pet Treats. Food Research International, 44, 193-197. https://doi.org/10.1016/j.foodres.2010.10.041

[29] Mai, H.M., Zahraddeen, D., Qadeera, M.A., Bawa, I.A. and Echeonwu, I.E. (2013) Investigation of Some Species of Salmonella in Table Eggs Sold at Different Markets in Jos South, Plateau State, Nigeria. Global Advanced Research Journal of Microbiology, 140, 131-135.

[30] Berchieri Jr., A., Murphy, C.K., Marston, K. and Barrow, P.A. (2001) Observations on the Persistence and Vertical Transmission of Salmonella Enteric Serovars Pullorum and Gallinarum in Chickens: Effect of Bacterial and Genetic Background. Avian Pathology, 30, 221-321. https://doi.org/10.1080/03079450120054631

[31] Ndiaye, M.L., Dieng, Y., Niang, S., Pfeifer, H.R., Tonolla, M. and Peduzzi, R. (2012) Effect of Irrigation Water on the Incidence of Salmonella spp. on Lettuce Produced Urban Agriculture and Sold in Markets in Dakar Senegal. African Journal of Microbiology Research, 5, 2885-2890.

[32] Bagudo, A.I., Tambuwal, F.M., Faleke, O.O., Egwu, O.O. and Aliero, A.A. (2014) Prevalence of Salmonella Serotypes in Sokoto Abattoir Effluents and Vegetables Cultivated around the Abattoir. Microbiology Research International, 2, 13-17. 